\title{
Clinical epidemiology of epithelial ovarian cancer in the UK
}

This article was published in the following Dove Press journal:

International Journal of Women's Health

23 May 2014

Number of times this article has been viewed

\section{Konstantinos Doufekas \\ Adeola Olaitan \\ Department of Gynaecological Oncology, University College London Hospitals, London, UK}

Video abstract

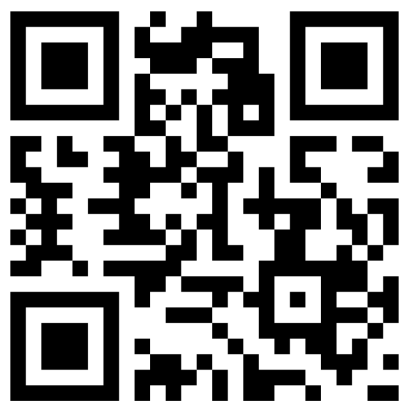

Point your SmartPhone at the code above. If you have a QR code reader the video abstract will appear. Or use: http://dvpr.es/lgVl19kf
Correspondence: Adeola Olaitan Department of Gynaecological Oncology, University College London Hospitals, 2nd Floor East, 250 Euston Road, London, UK, NWI 2PB

Tel +442034478636

Fax +4434479883

Email adeola.olaitan@uclh.nhs.uk
Abstract: Epithelial ovarian cancer is the fifth commonest cancer among women and the leading cause of gynecological cancer death in the UK. Most women present with advanced disease, mainly because the nonspecific nature of the symptoms lead to diagnostic delays. Recent data have shown a fall in ovarian cancer mortality rates in the UK, but rates are still higher when compared to other European countries or the USA. In addition, surgeons in the UK achieve on average lower optimal surgical cytoreduction rates in patients with advanced ovarian cancer. Despite a wealth of information on epidemiological risk factors, the pathogenesis of epithelial ovarian cancer remains largely unknown. This review presents the most recent data on incidence, mortality, and survival for epithelial ovarian cancer in the UK. Time trends, trends by age, international comparisons, and regional variation in incidence, survival, and mortality are presented within the context of a major reorganization of cancer services that took place in the UK over 10 years ago. Centralization of cancer services has meant that women with ovarian cancer receive treatment in specialist Cancer Centers.

Keywords: ovarian, cancer, epidemiology, UK, incidence, survival

\section{Introduction}

Epithelial ovarian cancer (EOC) is the fifth most common cancer among women and the leading cause of death from gynecological cancer in the UK. ${ }^{1,2}$ Each year more than 6,500 women are diagnosed with ovarian cancer in the UK and about 4,400 women die of the disease. . $^{3,4}$

Over the past 20 years the incidence of ovarian cancer in England has remained fairly static, but mortality rates have fallen by over $20 \%$ since $2000 .{ }^{5}$ However, the outlook for women with ovarian cancer remains poor, with an overall 5 -year survival rate below $45 \%{ }^{3}$

Large epidemiological studies have reported substantial differences in ovarian cancer survival in the UK when compared to other European countries, Australia, and Canada. ${ }^{1,6,7}$ This is in spite of the UK having a lead role in both research and training, conducting many of the major trials in ovarian cancer research, and being the first European country to implement formal gynecological oncology training.

The aim of this review is to present an overview of clinical epidemiology for EOC in the UK, with an emphasis on incidence, mortality, and survival trends.

Late presentation and lack of effective screening impede early detection of ovarian cancer. There are often delays between onset of symptoms and diagnosis and as a result, most women present with advanced stage disease, when cure rates are low. The current standard of care is cytoreductive surgery and platinum-based chemotherapy. 
Most ovarian cancers originate from the surface epithelium of the ovary. The majority of EOCs are sporadic, although a small percentage are familial and have a genetic etiology. The sporadic group of EOC presents a major challenge in defining the etiology of the disease. The role of some factors, such as parity, is well defined, while the role of others, such as the use of ovulation-inducing drugs, remains controversial. ${ }^{8}$

The National Health System in the UK is one of the largest health care systems in the world. ${ }^{9}$ In a white paper, ${ }^{10}$ (Equity and excellence: Liberating the NHS, 2010), the UK government proclaimed a strategy to achieve outcomes in cancer that are among the best in the world. ${ }^{9}$

\section{Overview of the UK National Health System}

The UK National Health Service (NHS) is the world's largest publicly funded health service. ${ }^{11}$ The clinical sector is divided into primary, secondary, and tertiary care. Primary care is provided by general practitioners (GPs). Secondary or hospital-based care is accessed through GP referral, and tertiary care includes specialist hospitals.

The 1995 Calman-Hine report prompted a massive reorganization of the UK's cancer services. ${ }^{12}$ The report proposed a strategy to improve outcomes and reduce inequalities in NHS cancer care. The 1999 Improving Outcomes Guidance $^{13}$ and subsequent NHS Cancer Plan ${ }^{14}$ provided further specifications of this new strategy. Cancer Networks were established with an emphasis on multidisciplinary team cancer specialist care. ${ }^{15}$ These networks incorporate a number of cancer units responsible for rapid diagnosis which then refer high risk patients to a cancer center for further management by trained gynecological oncologists. A sufficient concentration of work can thus be achieved in cancer centers to maintain expertise. ${ }^{16}$ There are currently 41 cancer centers within Cancer Networks in England. Centralization of care for women with ovarian cancer has been the subject of debate, ${ }^{17,18}$ but evidence from a recent meta-analysis ${ }^{19}$ indicates that centralization of care for gynecological cancer improves overall survival.

Until March 2013, ten strategic health authorities (SHAs) managed the NHS at the regional level and primary care trusts commissioned primary, community, and secondary health services from providers. New organizations such as clinical commissioning groups are now replacing the old NHS structure. ${ }^{11}$

\section{Data collection}

The United Kingdom has one of the most comprehensive cancer registration systems in the world. ${ }^{20}$ Eleven cancer registries covering England, Wales, Scotland, and Northern Ireland collate the data on incidence, mortality, and survival of ovarian cancer. ${ }^{20,21}$ Data are then analyzed and published by the Office of National Statistics (ONS). There is a 2-year lag between event recording and the publication of summary statistics by cancer registries and the ONS. ${ }^{21}$ Data completeness is high for diagnosis and deaths, but more variable information is recorded on management and treatment. ${ }^{21}$ The National Cancer Intelligence Network (NCIN) uses information collected by cancer registries for analysis, publication, and research. The Trent Cancer registry is NCIN's lead registry in England for gynecological cancers.

International comparisons can be made with global and European data from GLOBOCAN and EUROCARE projects and the International Cancer Benchmarking Partnership (ICBP).

\section{Definition}

In the latest NCIN report "Ovarian Cancer: Incidence, Mortality and Survival," ovarian cancer is defined according to the second edition of the International Classification of Diseases for Oncology (ICD-0-2). ${ }^{5}$ The ICD-0-2 classification includes "borderline tumors" within the category of "malignant ovarian neoplasms."

The ICD-0-2 was introduced in England and Wales in 1995, followed by Northern Ireland in 1996 and Scotland in 1997. The newer third edition of the International Classification of Diseases for Oncology (ICD-0-3) has removed borderline tumors from malignant ovarian neoplasms.

The ICD-0-3 classification has been used in the ICBP and EUROCARE reports. ${ }^{6,7}$ Consequently, the survival estimates in ICBP and EUROCARE appear lower than the survival estimates of the NCIN report. ${ }^{5}$

\section{Morphology}

Fifty to sixty percent of ovarian neoplasms are epithelial in origin and the most common histological subtype in the UK is serous carcinoma. ${ }^{22}$ Serous subtype accounted for one-third of all cases in 2009, being commonest in women aged 45 and over. ${ }^{5}$ Unclassified EOC was the second commonest type and was commonest in women older than 75 . Women with unclassified EOC have the worse mortality.

Over the past 10 years, there has been a 30\% decrease in the number of unclassified cases and a $38 \%$ increase in the number of serous ovarian cancers..$^{5}$ The relative frequency of other subtypes has remained fairly stable. The decrease in the number of unclassified epithelial cases may have resulted 
from better coding and recording of ovarian cancer morphology by cancer registries. ${ }^{5}$

\section{Stage}

In the UK, cancer registries use the TNM classification to stage cancer, similar to the International Federation of Gynecology and Obstetrics staging. TNM staging is derived on the basis of information obtained from surgery, imaging, and histopathology. Currently, data on ovarian cancer stage at presentation are only available from the Welsh Cancer Intelligence and Surveillance Unit ${ }^{21}$ and the East Anglia Registry.

Most women in the UK are diagnosed with advanced stage disease. Sixty percent present in stages III and IV and only around $30 \%$ are diagnosed in the early stages I and II. Over the past 20 years there has been a clear improvement in 5 -year survival for patients with stage I disease, an increase from $80 \%$ to $92 \%$. In stage II disease, 5-year survival increased from $30 \%$ to $55 \%$, but the confidence intervals are wide, thus making conclusions less certain. ${ }^{3}$ A small but consistent increase in 5-year survival has been seen in stage III disease, but the national average figure remains low at $22 \%$. $^{3}$ Survival in patients with stage IV disease has remained static and only $5.6 \%$ are still alive at 5 years. ${ }^{3}$ The International Federation of Gynecology and Obstetrics Committee on Gynecologic Oncology has recently published a revised staging classification for cancer of the ovary, fallopian tube, and peritoneum. ${ }^{23}$

\section{Etiology}

The pathogenesis of ovarian cancer remains controversial even though epidemiological studies have gleaned an enormous amount of information. ${ }^{8}$ Most studies have focused on the epidemiology of invasive EOC. ${ }^{24}$ The role of some factors, such as parity, is well established whereas the role of others such as infertility and its treatment remains more controversial. The evidence base for these associations has been elegantly discussed in previous reviews. ${ }^{8}$ A brief summary of some salient risk factors is presented below.

\section{Age}

Data from the US Surveillance, Epidemiology, and End Results database have clearly demonstrated that age bears a strong relation to ovarian cancer risk. ${ }^{8}$ The incidence is low in women under the age of 40 , but rises steeply after the fifth decade to reach a peak in the 80- to 84-year old age group (incidence of 61.8 per 100,000 women). ${ }^{8}$ The median age at diagnosis is currently 63 years. ${ }^{1,2,25,26}$ With an aging population in the UK and other Western countries, the total number of ovarian cancer cases can be expected to rise.

\section{Family history}

Genetic susceptibility is an important risk factor for ovarian cancer, and approximately $10 \%$ of ovarian cancer cases are caused by mutations that cluster in families. ${ }^{27}$ Mutations in the $B R C A 1$ and $B R C A 2$ genes are responsible for approximately $90 \%$ of inherited predispositions to ovarian cancer. ${ }^{28,29}$ Mutations at the hereditary nonpolyposis colorectal cancer gene and other loci account for the remaining. The lifetime risk of ovarian cancer in $B R C A$ mutation carriers ranges from $15 \%-60 \%{ }^{28,30}$ Screening for ovarian cancer in women who carry $B R C A$ mutations has been the focus of UK familial ovarian cancer screening study trial. ${ }^{31}$

\section{Reproductive factors}

\section{Parity and breastfeeding}

The effect of increasing parity in reducing the risk is now well established. ${ }^{8,32,33}$ Studies have shown a reduction in risk reduction even with incomplete pregnancies. ${ }^{34}$ Breastfeeding also seems to have a small protective effect. ${ }^{34}$

\section{Menstrual life}

Two large studies have failed to show a significant effect of either early menarche or late menopause on ovarian cancer risk. ${ }^{34,35}$ Length of menstrual cycle is therefore unlikely to be a significant factor in the pathogenesis of ovarian cancer.

\section{Infertility and its treatment}

The role of infertility and infertility therapy remains less clear. Studies have shown a trend towards an increased risk of ovarian malignancies in infertile women. ${ }^{8}$ The risk seems to be highest in a subset of women with unexplained infertility. ${ }^{8,36}$ Currently, there is no proven association between ovarian cancer and infertility treatment. ${ }^{37,38}$

\section{Exogenous hormones}

\section{The combined contraceptive pill}

Oral contraceptive use confers long-term protection against ovarian cancer. ${ }^{8,32,39-42}$ The longer the use, the greater the reduction in risk and the longer it persists. ${ }^{41}$ The use of oral contraceptives is associated with a reduced risk of ovarian cancer in women carrying a $B R C A$ mutation. ${ }^{43}$

\section{Hormone replacement therapy}

Hormone replacement therapy use increases the risk of ovarian cancer, but several small studies and a meta-analysis have 
shown only a small increase in risk, especially with more than 10 years of use. ${ }^{44,45}$ Short-term use is unlikely to increase the risk of ovarian cancer.

\section{Medical conditions}

\section{Endometriosis}

Women with endometriosis have an increased risk of developing ovarian cancer. ${ }^{46,47}$ There is an association especially with endometrioid and clear cell morphology. ${ }^{48}$ Unilateral oophorectomy, as well as radical resection of visible endometriosis, reduces the risk of later developing ovarian cancer. $^{49}$

\section{Previous cancer}

Studies have shown a twofold increase in the risk of ovarian cancer in women with a history of breast cancer. ${ }^{50,51}$ The risk may increase fourfold if their breast cancer is diagnosed before the age of 40, and manyfold if they also have a family history of breast or ovarian cancer. ${ }^{50}$ Radiotherapy treatment for cervical cancer also carries a long-term risk of cancer in the ovaries. ${ }^{52}$

\section{Other factors}

The sociodemographic behavior of women has undergone important changes over the past 40 years that may influence the incidence of ovarian cancer. Women's ever increasing participation in the workforce often delays childbearing until later in reproductive life. The mean age of women at childbirth in the UK has continued to rise. It was 29.5 years in 2010 compared with 28.5 years in 1995 and 27.2 years in $1962 .{ }^{53}$ Oral contraceptive use has become more widespread and may be expected to also have an influence on the incidence of ovarian cancer. ${ }^{54}$

\section{Epidemiology}

Detailed summary statistics on ovarian cancer in England and UK can be found in recent publications by NCIN and the National Institute for Health and Care Excellence (NICE). ${ }^{5,21}$ NCIN's latest report, "Overview of Ovarian Cancer in England: Incidence, Mortality and Survival," was released in 2012, and provides a detailed analysis of ovarian cancer statistics in England up to 2009. ${ }^{5}$ NICE released national (UK) epidemiology data in 2011, as part of a Clinical Guideline on the recognition and management of ovarian cancer. ${ }^{21}$ Cancer Research UK, have also produced descriptive statistics on ovarian cancer. ${ }^{3}$

\section{Incidence}

Ovarian cancer incidence rates vary considerably worldwide and across Europe. The highest rates have been recorded in
Central America and Northern, Central, and Eastern Europe. The UK has ranked sixth among the 27 countries in the European Union. ${ }^{55}$ In 2010 7,011 new cases of ovarian cancer were diagnosed in the $\mathrm{UK}^{3}$

\section{Variation with age}

Ovarian cancer is predominantly a disease of older women and its incidence rises steeply after the usual age of menopause. Over $80 \%$ of new diagnoses are in women over the age of $50 .^{5}$

Incidence reaches a peak in women over the age of 75 . This is true for all morphological types of ovarian cancer. In 2009 , almost half of new ovarian cancer diagnoses were in women over the age of 60 years $(2,817$ out of 5,849$) .{ }^{5}$

\section{Trends in ovarian cancer incidence}

The age-standardized incidence rate (ASIR) of ovarian cancer in the UK has increased from 14.7 per 100,000 female population in 1975 to 16.4 per 100,000 in $2007 .{ }^{21}$ Incidence rates peaked between 1995 and 1999, which may have been due to the introduction of the ICD-O-2 classification in the UK. ${ }^{21}$ The ICD-O-2 was introduced in England and Wales in 1995 and by 1997 it was also in use in Scotland and Northern Ireland.

Ovarian cancer in England has been the focus of NCIN's recently published report. ${ }^{5}$ In England, over the past two decades, the incidence of ovarian cancer has remained fairly static. It has shown minor fluctuations, and there has been a clear downward trend over the past few years. From 1989 to 1994, the ASIR of ovarian cancer ranged between 17 and 18 per 100,000 . The rate rose to around 19 per 100,000 between 1995 and 2003, only to return to 17 to 18 per 100,000 after 2004, similar to rates in the early 1990 s. In 2009, in England there were just fewer than 5,900 new diagnoses.

Over a period from 1989 to 2009, incidence rates in England showed varying trends in different age groups. In women aged 49 or less, incidence rates have remained fairly static at around 9 per 100,000. In women aged 50-69, incidence decreased from 48 to 40 per 100,000. In those over 70 , it increased from 57 to 70 per 100,000 between 1989 and 1999, but has decreased after 2000.

The decrease in incidence among women aged 50 and over may reflect the protective effect of the combined contraceptive pill that has been in widespread use since the 1960s. Women who are currently over the age of 70 belong to the first cohort of women that gained access to the oral contraceptive pill, after it became widely available in the 1960s. 


\section{Regional variation in incidence}

The incidence of ovarian cancer shows some variation across the constituent countries of the UK. Data from $2008^{56}$ indicate that Wales has the highest incidence rates followed by Scotland, Northern Ireland, and England.

Data from SHAs and Cancer Networks within England also indicate regional variation. ${ }^{5}$ Data from England over 2007 to 2009 show that the ASIR was lowest for women living in the Southeast coast and London SHAs and highest in East Midlands, Southwest, and South Central SHAs. Variation in incidence rates within Cancer Networks broadly reflects the trend seen across SHAs. Incidence rates appear highest in the Peninsula and lowest in the Southeast London Cancer Networks with ASIRs of 20.2 and 13.7 per 100,000 women, respectively. The average ASIR in England from 2007 to 2009 was 17.5 per 100,000 female population.

There is no evidence to suggest a correlation between deprivation and ovarian cancer incidence among various primary care trusts in England. ${ }^{5}$

\section{Mortality}

Ovarian cancer is the leading cause of death in gynecological cancer in both the United Kingdom and worldwide. In 2008 , around 4,400 women died from ovarian cancer in the UK. Data from EUROCARE suggest that the UK has higher mortality rates when compared to the other European countries. ${ }^{1,6}$

Fifteen percent of women diagnosed with ovarian cancer in the UK in 2006-2008 died within 2 months, while onethird died within the first year. ${ }^{5,21}$

Death within the first year is a reflection of presentation with advanced disease.

\section{Trends in ovarian cancer mortality over time}

The mortality rate for ovarian cancer in the UK has fallen by $20 \%$ over the past decade. ${ }^{5}$ Age-standardized mortality rates were stable between 1989 and 2002, ranging from 11 to 12 per 100,000 , but had fallen to 8.8 per 100,000 by $2010 .^{5}$ The reduction in mortality over the past decade coincided with the reconfiguration of cancer services and may reflect enhanced cancer care with better detection and management within the UK specialist gynecological cancer centers.

Mortality has shown varying trends across different age groups. National data from 1971 to 2008 show that in women over 65 years of age there has been a gradual increase in mortality. ${ }^{21}$ In women aged 50 to 64 years there has been steady decline and in those under 49 years the mortality rate has been fairly constant. ${ }^{21}$

\section{Geographical variation}

The age-standardized mortality rates are similar across the constituent countries in the UK. The highest mortality rate is seen in Northern Ireland and the lowest in Wales. Within England, mortality rates are highest in West Midlands and South Central SHAs and lowest in London and Yorkshire and the Humber SHAs. ${ }^{5}$ A similar variation is noted within constituent Cancer Networks. Peninsula and Mid Trent Cancer Networks had the highest mortality and North London, West London, and Northeast London Cancer Networks the lowest. ${ }^{21}$

There is no evidence that deprivation is related to ovarian cancer mortality. ${ }^{5}$

\section{Survival}

Ovarian cancer survival rates remain the lowest among gynecological cancers, both in the UK and worldwide. ${ }^{5,21}$ Women often present late, with advanced staged disease and this has a major negative impact on survival.

\section{Variation with age}

Survival is strongly related to age and younger women have a better prognosis.

Data from the UK Cancer Information Service (UKCIS) provide strong evidence of a worse survival from ovarian cancer in older women. In England for example, over a period from 2003 to 2009 women aged 15-39 achieved 1-year survival of $95.6 \%$ compared to a mere $24 \%$ in women aged over $85 .{ }^{5}$ Five-year survival showed a similar dramatic variation with age. In England over the same time period, the 5-year survival in the 15-39 age group was $84.2 \%$ compared with $13.7 \%$ in those aged over $85 .^{5}$

These differences in relative survival partly reflect differences in tumor biology, as well as the higher proportion of borderline tumors in women of younger age. Other factors may, however, also contribute to the gap in survival between older and younger patients. Evidence from the General Practice Research Database suggests that GPs may be less likely to both diagnose and to refer women for gynecological investigation as they get older. ${ }^{3,57}$ There are also often difficulties in treating older women with both surgery and chemotherapy, related to medical comorbidities or a low performance status.

In addition, data from the NCIN show that over the past 20 years, both 1-year and 5-year survival in women over 80 
has failed to improve, despite the notable improvement in all other age groups. ${ }^{5}$

\section{Trends in survival}

In the UK, both 1-year and 5-year survival have improved since the mid-1980s, similar to other European countries. ${ }^{6,7}$ In England for example, from 1985 to 2009 1-year survival increased from $57 \%$ to $73 \%$ and 5-year survival from $33 \%$ to $43 \%$.

Since 1987, the greatest improvement in 1-year survival was seen in women aged 55-79, whereas the greatest improvement in 5-year survival was seen in the 40-49 age group. ${ }^{5}$

These significant improvements may reflect the effect of the new government strategies in gynecological cancer through the establishment of Cancer Networks, specialist centers, and oncology multidisciplinary teams. Surgery for ovarian cancer is now centralized and provided by subspecialist gynecological oncologists. Chemotherapy regimens have also improved and combined taxane-platinum chemotherapy is now the standard treatment. ${ }^{5}$ There is evidence that women who receive treatment for ovarian cancer in specialized centers have longer survival than those managed elsewhere. ${ }^{19}$

\section{Geographical variation}

The latest NCIN data for England from 2003-2009 provide evidence of cancer survival inequalities, with marked geographical variation for both 1-year and 5-year survival in ovarian cancer. One-year survival is highest in Southwest London, Pan Birmingham, and Yorkshire Cancer Networks. The Pan Birmingham Cancer Network also shows the highest 5-year survival rate, along with North of England. In contrast, Sussex Cancer Network demonstrates geographical clustering of poor survival, with both 1-year and 5-year rates well below the national average. ${ }^{5}$ These regional disparities in ovarian cancer survival may be due to several factors, including differential delays in referral and diagnosis and differences in treatment or comorbidities among patients. Variable quality of data capture across Cancer Networks may also be behind regional inequalities. ${ }^{58}$

\section{International variation}

Despite the improvement in survival that has occurred in recent years, data from EUROCARE and the ICBP show that survival rates in the UK are still lower than in other European countries, Australia, and Canada. ${ }^{1,6,7,59}$ This is in spite of the UK having a similar health care system and similar percentage of women diagnosed at different stages of the disease to other developed countries. Differences in coding and quality of data collection between countries may account for some of the noted differences.

Survival rates in the UK are highest in Northern Ireland, followed by Wales, Scotland, and England. ${ }^{7,59}$ In Europe, the highest survival rates are found in Scandinavia, Switzerland, and Austria. ${ }^{59}$

Delays in accessing treatment through primary care or differences in the quality of care could account for the lower survival rate in the UK. ${ }^{60}$ A large percentage of patients diagnosed with ovarian cancer in the UK continue to present as an emergency. In 2007, for example, almost one-third of such patients presented as an emergency. ${ }^{5}$

Differences in other factors, including public awareness of cancer, comorbidity, and access to optimal treatment, may also explain the survival deficit in the UK. ${ }^{7}$

\section{Routes of diagnosis}

The NCIN has recently published data on the different pathways patients follow to reach a diagnosis of ovarian cancer. ${ }^{21}$ These include routine and urgent GP referrals for symptoms of malignancy, and other elective outpatient, inpatient, and emergency presentations. The data refer to English patients diagnosed with ovarian cancer between 2006 and 2008. They highlight a wide variation in the way patients enter the diagnostic pathway. The majority of ovarian cancer patients (64\%) attend electively, but one-third (30\%) still presents as an emergency. Urgent GP referrals account for almost one-quarter of all presentations. As emergency presentation is associated with increased mortality, ${ }^{61}$ it remains a major challenge in the UK to reduce the proportion of patients who present via the emergency route.

\section{Treatment}

Ovarian cancer treatment usually consists of surgery and/or combination chemotherapy, depending on stage at presentation.

Staging for ovarian cancer is surgico-pathological. In women with suspected early (stage I) ovarian cancer, complete surgical staging includes total abdominal hysterectomy, bilateral salpingo-oophorectomy, omentectomy, random peritoneal biopsies, and block dissection of the ipsilateral pelvic and paraaortic nodes. The NICE guidelines do not advocate systematic lymphadenectomy as part of standard surgical treatment, ${ }^{21}$ and this may lead to routine under-staging. ${ }^{62,63}$ This guidance is not accepted by the British Gynaecological Cancer Society. ${ }^{64}$

In advanced disease, the European Organisation for Research and Treatment of Cancer 55971 and Medical 
Research Council CHORUS trial have assessed the impact of the timing of surgery and chemotherapy. ${ }^{65,66}$ They both indicate that delayed primary surgery does not have a negative impact on survival and may reduce perioperative morbidity. ${ }^{65,66}$

There is lack of national comparative data on treatment modalities in the UK. Cancer centers have been slow to develop comprehensive databases and publish their outcome data. ${ }^{67}$

Data on surgical treatments in ovarian cancer have been published for Wales by the Welsh Cancer Intelligence and Surveillance Unit. ${ }^{21}$ The most frequent procedure undertaken in the three Welsh Cancer Networks is total abdominal hysterectomy, bilateral salpingo-oophorectomy, and omentectomy as part of a staging laparotomy. Data from England are yet to be published.

When compared to the USA and Europe, the UK achieves on average low optimal surgical cytoreduction rates in advanced ovarian cancer. ${ }^{65,66}$ Possible reasons for this discrepancy have been explored previously and may include operating time constraints within NHS hospitals. ${ }^{67,68}$ The Medical Research Council CHORUS trial reported zero residual disease in $15 \%$ of primary and $35 \%$ of interval debulking surgery, with an average duration of surgery of 2 hours. ${ }^{66}$

In the North London Cancer Network, University College London Hospital currently achieves (based on internal audit results) optimal cytoreduction rates of around 70\% for upfront surgery in advanced ovarian cancer. This is comparable to data reported by other major centers, such as the Mayo clinic. ${ }^{69}$

Data on chemotherapy use from two Cancer Networks have revealed a marked variation between hospitals in the percentage of patients receiving chemotherapy. Up to $40 \%$ of older patients were managed with chemotherapy alone. ${ }^{21}$

There is however, evidence that more ovarian cancer patients receive specialist treatment in England, as per the Improving Outcomes Guidance. From 2000 to 2007 the percentage of women with ovarian cancer operated on by specialists increased from $17 \%$ to $48 \%$ and the percentage treated in specialist centers increased from $40 \%$ to $71 \%{ }^{70}$

Currently, ovarian cancer patients in the UK receive intraperitoneal chemotherapy only as part of the PETROC/ OV21 trial.

\section{Conclusion}

Ovarian cancer incidence in the UK has remained fairly stable over at least two decades, although in recent years there have been slight decreases in incidence. Mortality rates have fallen by $20 \%$ since $2002 .{ }^{5}$ One-year and 5-year survival following a diagnosis of ovarian cancer have both improved significantly over the past two decades, although there has been little or no improvement in survival rates of the oldest women. Despite this, ovarian cancer remains the leading cause of gynecological cancer death.

These trends have coincided with the centralization of UK cancer services, which followed the Improved Outcomes Guidance by the Department of Health over a decade ago. Women with ovarian cancer in the UK receive treatment by specialist gynecologic oncologists in tertiary referral centers.

However, regional variations in ovarian cancer mortality and survival in the UK still exist, and it remains a challenge to synchronize underperforming Cancer Networks with national average scores.

In addition, survival remains lowest in all three UK nations when compared to many other European countries. ${ }^{6}$ The wide differences in survival may be explained by diagnostic delays and variation in accessing optimal treatment in the UK. ${ }^{7}$ Correcting the UK survival deficit should be a focus for policy makers in the UK and will remain a key indicator of progress.

Surgical centers in the UK need to develop and maintain comprehensive databases which could yield a wealth of data on outcomes such as morbidity, mortality, and survival. It also remains a challenge to increase optimal cytoreduction rates nationally and to avoid diagnostic delays within primary care, as both of these factors can have a negative impact on survival.

Although epidemiological studies have provided a wealth of information on the role of various risk factors, there is still little consensus regarding the origins and pathogenesis of EOC.

\section{Disclosure}

The authors report no conflicts of interest in this work.

\section{References}

1. Berrino F, De Angelis R, Sant M, et al; EUROCARE Working group. Survival for eight major cancers and all cancers combined for European adults diagnosed in 1995-1999: results of the EUROCARE-4 study. Lancet Oncol. 2007;8(9):773-783.

2. Ferlay J, Bray F, Pisani P, Parkin DM. GLOBOCAN 2002. Cancer Incidence, Mortality and Prevalence Worldwide. IARC Cancer Base No 5, Version 2.0. Lyon: IARC Press; 2004

3. Ovarian cancer statistics [webpage on the Internet]. Oxford: Cancer Research UK; 2013 [updated Jan 2013]. Available from: http://www. cancerresearchuk.org/cancer-info/cancerstats/types/ovary/. Accessed January 10, 2014

4. Targeted Therapies for the Management of Ovarian Cancer (Scientific Impact Paper No 12) [webpage on the Internet]. London: Royal College of Obstetricians and Gynaecologists; 2013. Available from: http://www.rcog. org.uk/womens-health/clinical-guidance/targeted-therapies-managmentovarian-cancer. Accessed January 10, 2014. 
5. Overview of Ovarian Cancer in England: Incidence, Mortality and Survival (Nov 2012) [webpage on the Internet]. London: National Cancer Intelligence Network. Available from: http://www.ncin.org.uk/ cancer_type_and_topic_specific_work/cancer_type_specific_work/ gynaecological_cancer/gynaecological_cancer_hub/resources/ ovarian_cancer. Accessed January 10, 2014.

6. De Angelis R, Sant M, Coleman MP, et al; EUROCARE-5 Working Group. Cancer survival in Europe 1999-2007 by country and age: results of EUROCARE-5-a population-based study. Lancet Oncol. 2014;15(1):23-34.

7. Coleman MP, Forman D, Bryant H, et al; ICBP Module 1 Working Group. Cancer survival in Australia, Canada, Denmark, Norway, Sweden, and the UK, 1995-2007 (the International Cancer Benchmarking Partnership): an analysis of population-based cancer registry data. Lancet. 2011;377(9760):127-138.

8. Edmondson RJ, Monaghan JM. The epidemiology of ovarian cancer. Int J Gynecol Cancer. 2001;11(6):423-429.

9. Grosios K, Gahan PB, Burbidge J. Overview of health care in the UK. EPMA J. 2010;1(4):529-534.

10. Equity and Excellence: Liberating the NHS. Department of Health publications; 2010. Available from: https://www.gov.uk/government/ uploads/system/uploads/attachment_data/file/213823/dh_117794.pdf. Accessed January 10, 2014.

11. The NHS in England [webpage on the Internet]. London: National Health Service; 2013. Available from: http://www.nhs.uk/NHSEngland/ thenhs/about/Pages/overview.aspx. Accessed January 10, 2014.

12. Morris E, Haward RA, Gilthorpe MS, Craigs C, Forman D. The impact of the Calman-Hine report on the processes and outcomes of care for Yorkshire's colorectal cancer patients. Br J Cancer. 2006;95(8):979-985.

13. Guidance on Commissioning Cancer Services: Improving Outcomes in Gynaecological Cancers-The Mannual. Department of Health; 1999. Available from: http://webarchive.nationalarchives.gov.uk/+/www. dh.gov.uk/en/Publicationsandstatistics/Publications/PublicationsPolicyAndGuidance/DH_4005385. Accessed January 10, 2014.

14. The NHS Cancer Plan: a Plan for Investment, a Plan for Reform. London: Department of Health; 2000. Available from: http://webarchive. nationalarchives.gov.uk/+/www.dh.gov.uk/en/Publicationsandstatistics/ Publications/PublicationsPolicyandGuidance/DH_4009609. Accessed January 10, 2014.

15. Characteristics of an Effective Multidisciplinary Team (MDT) [webpage on the Internet]. London: National Cancer Intelligence Network; 2010. Available from: http://www.ncin.org.uk/cancer_type_and_topic_ specific_work/multidisciplinary_teams/mdt_development. Accessed January 10, 2014.

16. Kitchener HC. Gynaecological cancer services: time for change. BJOG. 1997;104(2):123-126.

17. Olaitan A, McCormack M. Centralisation of services for the management of ovarian cancer: arguments for. BJOG. 2007;114(10):1188-1190.

18. Crawford SM, Brunskill PJ. Centralisation of services for the management of ovarian cancer: arguments against. BJOG. 2007;114(10):1183-1185; discussion 1186-1187.

19. Woo YL, Kyrgiou M, Bryant A, Everett T, Dickinson HO. Centralisation of services for gynaecological cancer. Cochrane Database Syst Rev. 2012;3:CD007945.

20. United Kingdom Association of Cancer Registries Home Page [homepage on the Internet]. United Kingdom Association of Cancer Registries; 2013. Available from: http://www.ukacr.org/. Accessed January 10, 2014.

21. National Institute for Health Care and Excellence. Ovarian Cancer: the Recognition and Initial Management of Ovarian Cancer. Full Guideline (Apr 2011). London: National Institute for Health Care and Excellence; 2012. Available from: http://www.nice.org.uk/nicemedia/ live/13464/54266/54266.pdf. Accessed January 10, 2014.

22. McCluggage WG. My approach to and thoughts on the typing of ovarian carcinomas. J Clin Pathol. 2008;61(2):152-163.

23. Prat J; FIGO Committee on Gynecologic Oncology. Staging classification for cancer of the ovary, fallopian tube, and peritoneum. Int J Gynaecol Obstet. 2014;124(1):1-5.
24. Tortolero-Luna G, Mitchell MF. The epidemiology of ovarian cancer. J Cell Biochem Suppl. 1995;23:200-207.

25. Kirwan J. Ovarian cancer standards of care. In: Acheson N, Luesly D, editors. Gynaecological Oncology for the MRCOG and Beyond. London: RCOG Press; 2010:115-143.

26. Parkin DM, Bray F, Ferlay J, Pisani P. Global cancer statistics 2002. $C A$ Cancer J Clin. 2005;55(2):74-108.

27. Ovarian cancer risks and causes [webpage on the Internet]. London: Cancer Research UK; 2013 [updated November 29, 2013]. Available from: http://www.cancerresearchuk.org/cancer-help/type/ovarian-cancer/ about/ovarian-cancer-risks-and-causes. Accessed January 10, 2014.

28. Ford D, Easton DF, Bishop DT, Narod SA, Goldgar DE. Risks of cancer in BRCA1 mutation carriers. Breast Cancer Linkage Consortium. Lancet. 1994;343(8899):692-695.

29. Boyd J. Molecular genetics of hereditary ovarian cancer. Oncology (Williston Park). 1998;12(3):399-406.

30. Easton DF, Ford D, Bishop DT. Breast and ovarian cancer incidence in BRCA1 mutation carriers. Breast Cancer Linkage Consortium. Am J Hum Genet. 1995;56(1):265-271.

31. Rosenthal A, Fraser L, Manchanda R, et al. Results of annual screening in phase I of the United Kingdom familial ovarian cancer screening study highlight the need for strict adherence to screening schedule. J Clin Oncol. 2013;31(1):49-57.

32. Risch HA, Marrett LD, Howe GR. Parity, contraception, infertility, and the risk of epithelial ovarian cancer. Am J Epidemiol. 1994;140(7): 585-597.

33. Adami HO, Hsieh CC, Lambe M, et al. Parity, age at first childbirth, and risk of ovarian cancer. Lancet. 1994;344(8932):1250-1254.

34. Whittemore A, Harris R, Itnyre J. Characteristics relating to ovarian cancer risk: collaborative analysis of 12 US case-control studies. IV. The pathogenesis of epithelial ovarian cancer. Collaborative Ovarian Cancer Group. Am J Epidemiol. 1992;136(10):1212-1220.

35. Hankinson SE, Colditz GA, Hunter DJ, et al. A prospective study of reproductive factors and risk of epithelial ovarian cancer. Cancer. 1995;76(2):284-290

36. Venn A, Watson L, Lumley J, Giles G, King C, Healy D. Breast and ovarian cancer incidence after infertility and in vitro fertilization. Lancet. 1995;346(8981):995-1000.

37. Vlahos NF, Economopoulos KP, Creatsas G. Fertility drugs and ovarian cancer risk: a critical review of the literature. Ann N Y Acad Sci. 2010;1205:214-219.

38. Zreik TG, Ayoub CM, Hannoun A, Karam CJ, Munkarah AR. Fertility drugs and risk of ovarian cancer: dispelling the myth. Curr Opin Obstet Gynecol. 2008;20(3):313-319.

39. Tsilidis KK, Allen NE, Key TJ, et al. Oral contraceptive use and reproductive factors and risk of ovarian cancer in the European Prospective Investigation into Cancer and Nutrition. Br J Cancer. 2011;105(9): 1436-1442.

40. Tworoger SS, Fairfield KM, Colditz GA, Rosner BA, Hankinson SE. Association of oral contraceptive use, other contraceptive methods, and infertility with ovarian cancer risk. Am J Epidemiol. 2007;166(8): 894-901.

41. Collaborative Group on Epidemiological Studies of ovarian Cancer, Beral V, Doll R, Hermon C, Peto R, Reeves G. Ovarian cancer and oral contraceptives: collaborative reanalysis of data from 45 epidemiological studies including 23,257 women with ovarian cancer and 87,303 controls. Lancet. 2008;371(9609):303-314.

42. Vessey MP, Painter R. Endometrial and ovarian cancer and oral contraceptives- findings in a large cohort study. $\mathrm{Br} J$ Cancer. 1995;71(6):1340-1342.

43. McLaughlin JR, Risch HA, Lubinski J, et al; Hereditary Ovarian Cancer Clinical Study Group. Reproductive risk factors for ovarian cancer in carriers of BRCA1 or BRCA2 mutations: a case-control study. Lancet Oncol. 2007;8(1):26-34.

44. Garg PP, Kerlikowske K, Subak L, Grady D. Hormone replacement therapy and the risk of epithelial ovarian carcinoma: a meta-analysis. Obstet Gynecol. 1998;92(3):472-479. 
45. Beral V; Million Women Study Collaborators, Bull D, Green J, Reeves G. Ovarian cancer and hormone replacement therapy in the Million Women Study. Lancet. 2007;369(9574):1703-1710.

46. Modugno F, Ness RB, Allen GO, Schildkraut JM, Davis FG, Goodman MT. Oral contraceptive use, reproductive history, and risk of epithelial ovarian cancer in women with and without endometriosis. Am J Obstet Gynecol. 2004;191(3):733-740.

47. Borgfeldt C, Andolf E. Cancer risk after hospital discharge diagnosis of benign ovarian cysts and endometriosis. Acta Obstet Gynecol Scand. 2004;83(4):395-400.

48. Heaps JM, Nieberg RK, Berek JS. Malignant neoplasms arising in endometriosis. Obstet Gynecol. 1990;75(6):1023-1028.

49. Melin AS, Lundholm C, Malki N, Swahn ML, Sparèn P, Berqqvist A. Hormonal and surgical treatments for endometriosis and risk of epithelial ovarian cancer. Acta Obstet Gynecol Scand. 2013;92(5):546-554.

50. Bergfeldt K, Rydh B, Granath F, et al. Risk of ovarian cancer in breast cancer patients with a family history of breast or ovarian cancer: a population based cohort study. Lancet. 2002;360(9337):891-894.

51. Ovarian cancer risk factors [webpage on the Internet]. Cancer Research UK [Updated November 2013]. Available from: http://www.cancerresearchuk.org/cancer-info/cancerstats/types/ovary/riskfactors/.Accessed March 31, 2014.

52. Chaturvedi AK, Engels EA, Gilbert ES, et al. Second cancers among 104,760 survivors of cervical cancer: evaluation of long term risk. J Natl Cancer Inst. 2007;99(21):1634-1643.

53. Bates C. More women putting off starting a family as average age of having a baby climbs to 29 [webpage on the Internet]. London: Mail Online; October 20, 2011. Available from: http://www.dailymail.co.uk/ health/article-2051374/Average-age-women-having-baby-climbs-29start-family-later.html. Accessed January 10, 2014.

54. Olaitan A, Mocroft A, Jacobs I. Patterns in the incidence of agerelated ovarian cancer in South East England 1967-1996. BJOG. 2000;107(9):1094-1096.

55. Ferlay J, Parkin DM, Steliarova-Foucher E. Estimates of cancer incidence and mortality in Europe in 2008. Eur J Cancer. 2010;46(4):765-781.

56. Ovarian cancer incidence statistics [webpage on the Internet]. London: Cancer Research UK; 2011 [updated November 4, 2011]. Available from: http://www.cancerresearchuk.org/cancer-info/cancerstats/types/ ovary/incidence/uk-ovarian-cancer-incidence-statistics. Accessed January 10, 2014.

57. Tate AR, Nicholson A, Cassell JA. Are GPs under investigating older patients presenting with symptoms of ovarian cancer? Observational Study using General Practice Research Database. Br J Cancer. 2010;102(6):947-951.

58. Walters S, Quaresma M, Coleman MP, Gordon E, Forman D, Rachet B. Geographical variation in cancer survival in England, 1991-2006: an analysis by Cancer Network. J Epidemiol Community Health. 2011;65(11):1044-1052.
59. Oberaigner W, Minicozzi P, Bielska-Lasota M, et al; Eurocare Working Group. Survival for ovarian cancer in Europe: the across-country variation did not shrink in the past decade. Acta Oncol. 2012;51(4): $441-453$.

60. Differences in treatment for advanced ovarian cancer could explain why UK survival lags behind other countries [webpage on the Internet]. London: Cancer Research UK; 2012 [updated October 3, 2012]. Available from: http://www.cancerresearchuk.org/about-us/cancernews/press-release/differences-in-treatment-for-advanced-ovariancancer-could-explain-why-uk-survival-lags-behind-other. Accessed January 10, 2014.

61. Short Term Ovarian Cancer Mortality [webpage on the Internet]. London: National Cancer Intelligence Network. Available from: http:// www.ncin.org.uk/publications/data_briefings/short_term_ovarian_ cancer_mortality. Accessed January 10, 2014.

62. Morice P, Joulie F, Camatte S, et al. Lymph node involvement in epithelial ovarian cancer: analysis of 276 pelvic and paraaortic lymphadenectomies and surgical implications. J Am Coll Surg. 2003;197(2): 198-205.

63. Chang SJ, Bristow RE, Ryu HS. Analysis of para-aortic lymphadenectomy up to the level of the renal vessels in apparent early-stage ovarian cancer. J Gynecol Oncol. 2013;24(1):29-36.

64. Olaitan A. NICE on ovarian cancer: Recommendations for detection in primary care are flawed. BMJ. 2011;342:d3022.

65. Vergote I, Tropé CG, Amant F, et al; European Organization for Research and Treatment of Cancer-Gynaecological Cancer Group; NCIC Clinical Trials Group. Neoadjuvant chemotherapy or primary surgery in stage IIIC or IV ovarian cancer. $N$ Engl J Med. 2010;363(10): 943-953.

66. Kehoe S, Hook J, Nankivell M, et al. Chemotherapy or upfront surgery for newly diagnosed advanced ovarian cancer: results from the MRC CHORUS trial. In: Proceedings of the 18th International Meeting of the European Society of Gynaecological Oncology; October 19-22, 2013; Liverpool, UK. Abstract 5500.

67. Naik R, Edmondson RJ, Galaal K, Hatem MH, Godfrey KA. A statement for extensive primary cytoreductive surgery in advanced ovarian cancer. BJOG. 2008;115(13):1713-1714; author reply 1714.

68. Pomel C, Barton DP, McNeish I, Shepherd J. A statement for extensive primary cytoreductive surgery in advanced ovarian cancer. BJOG 2008;115(7):808-810.

69. Aletti GD, Dowdy SC, Gostout BS, et al. Aggressive surgical effort and improved survival in advanced stage ovarian cancer. Obstet Gynecol. 2006;107(1):77-85.

70. Butler J, Gildea C, Meechan D, Nordin A. Ovarian Cancer Surgery by Specialists in Specialist Centres. Proceedings of the 2011 UKacr/NCIN conference: Liberating Information, Improving Outcomes; 2011 June 15-17; London, UK.
International Journal of Women's Health

\section{Publish your work in this journal}

The International Journal of Women's Health is an international, peerreviewed open-access journal publishing original research, reports, editorials, reviews and commentaries on all aspects of women's healthcare including gynecology, obstetrics, and breast cancer. The manuscript management system is completely online and includes

\section{Dovepress}

a very quick and fair peer-review system, which is all easy to use. Visit http://www.dovepress.com/testimonials.php to read real quotes from published authors. 